\title{
Overcrowded classrooms - The Achilles heel of South African education?
}

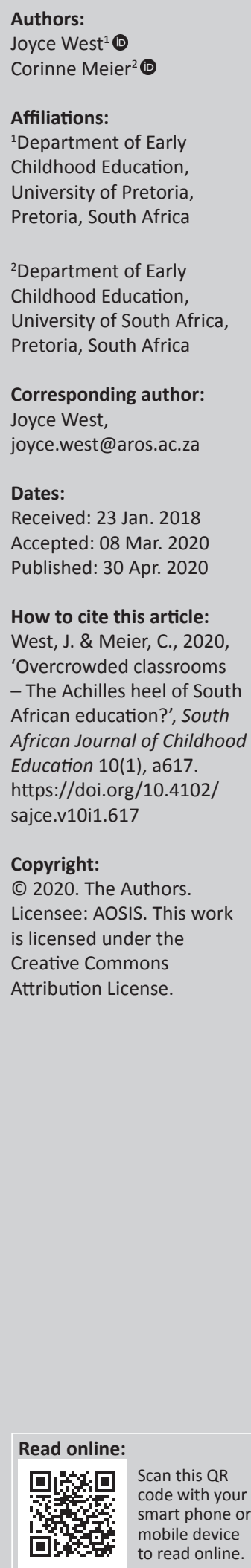

Background: The South African education system is characterised by a shortage of teachers and inadequate school infrastructure which is contributing to the overcrowded nature of South African classrooms. The current national learner-educator ratio (LER) is 33:1, and some classes have even reported an LER value of 50:1 and higher. The South African LER is more than double the average of the Organisation for Economic Co-operation and Development's international average of 16:1.

Aim: This research has been conducted to identify overcrowdedness in classrooms as a factor associated with poor academic achievement.

Setting: A qualitative research approach served this study best when an investigation was launched into the impact of overcrowded classrooms in the Foundation Phase in the TshwaneWest district.

Methods: The study's sample comprised 10 purposefully chosen participants who are knowledgeable and experienced in the field of teaching in overcrowded classrooms in the Foundation Phase. The participants included heads of departments, primary school principals, higher education lecturers and a department of basic education official. In-depth, semistructured interviews were conducted with each of the participants.

Findings: Based on the findings, the impact of and challenges (such as didactical neglect, discipline issues and negative teacher attitudes) related to overcrowdedness was elaborated on, and practical recommendations were made regarding possible solutions.

Conclusion: This study conclude by emphasising the importance of a combined effort between all role players, such as the School Management Teams and the teachers, when dealing with the challenges posed by overcrowdedness.

Keywords: challenges; fight or flight response; learner-educator ratio; overcrowdedness; stress; school management teams (SMTs); teachers.

\section{Introduction}

South Africa performs poorly in both national and international assessments, such as the Annual National Assessment (ANA ${ }^{1}$ ) and the Progress in International Reading Literacy Study (PIRLS). In the ANA Home Language (as referred to by the Curriculum and Assessment Policy Statement [CAPS]) tests conducted in 2014, Grade 1 learners reached an average of $63 \%$, Grade 2 learners had an average of $61 \%$ and Grade 3 learners had an average of 56\%. In the 2016 PIRLS assessment, the South African literacy results were also alarming. Grade 4 learners averaged a reading score of 320 out of a 1000 on the PIRLS scale ${ }^{2}$, which is concerning because it falls far below the PIRLS 'low international benchmark' of 400 (Mullis et al. 2017:20). This describes a disturbing picture of education and its 'outcome quality' in South African schools (Modisaotsile 2012:s.p.). These results indicate the urgency for improvement in the quality of education, especially during the Foundation Phase because it is one of the phases (early years of schooling: grades 1-3) that directly affect learners' academic success later in life (Department of Basic Education [DBE] 2014a:42). In 2008, the South African Ministerial Committee on Learner Retention observed high repetition rates as early as Grade 1 (Department of Education [DoE] 2008:xii). The then DoE reported that out of 1000 people born between 1980 and 1984 (aged 23-27 years in 2007), about 984 entered Grade 1 and only 456 reached Grade 12 . This means that not even $50 \%$ of this cohort who started Grade 1 reached Grade 12 (DoE 2008:xiii). 1.The ANA's are no longer used as a standardised measure of assessment in South Africa.

2.PIRLS depends on Item Response Theory (IRT) scaling to combine each participating country's learner population and to provide accurate estimates of learner reading achievement. 
South Africa's increasingly poor Grade 12 outputs and current retention rates further indicate that there is a crisis in education. One of the influential factors associated with poor performance and grade repetition is overcrowded classrooms. Overcrowded classrooms occur as a result of a shortage of teachers, a lack of school infrastructure and a high number of poorly resourced no-fee (quintiles 1-3) schools. When investigating these influential factors associated with grade repetition and poor performance, the factors can be divided into two categories: 'in-school' (i.e. supply side) and 'out-of-school' (i.e. demand side) factors (DoE 2008:xii, 70; Ndebele 2014:454). The 'in-school' factors include teachers' attitudes, the availability of trained teachers and school resources as well as adequate infrastructure, such as the availability of schools and classrooms. Examples of inadequate 'in-school' factors, such as a lack of resources and inadequate infrastructure, include $41.8 \%$ of schools without electricity, $70 \%$ of schools without access to computers, $79 \%$ of schools without libraries and overcrowded classrooms with an average learner-educator ratio $\left(\mathrm{LER}^{3}\right)$ of $33: 1$, that is, one teacher for every 33 learners (DBE 2013:85, 2014b:4; Ndebele 2014:463). 'Out-of-school' factors that have an impact on the repetition rates of learners include the socio-economic status of their family, levels of school readiness and parental involvement in schools (DoE 2008:70-72). This study investigated the impact of an 'in-school' factor, namely, overcrowded classrooms, with specific focus on the challenges teachers experience during teaching and learning.

According to the DBEs' (2013:85-86) annual performance plan of 2013/2014, an estimated amount of R5.3 billion has been set aside over the 2013/2014 to 2015/2016 Medium Term Expenditures Framework (MTEF) period for the construction of 91 new schools and the rehabilitation of 273 existing schools through a 'design and build' programme in collaboration with the Government Department of Infrastructure Development (GDID) (DBE 2013:85-86). More recently, the DBE has committed to provide appropriate and adequate basic education infrastructure by anticipating the spending of $51.4 \%$ (R40.4bn) of their total budget over the MTEF period on various activities related to school infrastructure. These activities are possible because of two infrastructure grants: the education infrastructure grant of R34.3bn and the school infrastructure backlogs grant of R6.1bn (DBE 2019:206).

Even though the DBE is currently investigating the possibility of eradicating backlogs, Skelton (2014:3-4), the United Nations Educational, Scientific and Cultural Organisation (UNESCO) Chair of Education Law in Africa and the Director of the Centre for Child Law, believes that the DBEs' strategic planning is questionable because they have underspent the Eastern Cape's Accelerated Schools Infrastructure Delivery Initiative (ASIDI) schools infrastructure backlog grant and term used in South Afric
international purposes. only delivered 10 schools, while their target was 49 schools. Skelton (2014:1) is also of the opinion that failure in improving school infrastructure in South Africa is because of the management capacity that is required by large infrastructure projects and according to her the DBE lacks proper management. Improving the school infrastructure remains a tiresome concern in South Africa for future quality education. Abdoll and Barberton (2014:viii) state that at the current infrastructure delivery rate, 2023/2024 is a realistic timeframe for the eradication of the schools infrastructure backlog. One result of a lack of infrastructure is overcrowdedness in classrooms. This study therefore was aimed to determine the effects of overcrowded Foundation Phase classrooms in the Tshwane-West district, which could possibly be the Achilles heel in South African education. The study also searched for possible solutions to this problem.

\section{Literature review}

When exploring the term 'overcrowdedness', it is necessary to determine the influential factors contributing to overcrowdedness as well as to investigate the impact of these factors. In the following sections, both the influential factors, as well as their impact on teaching and learning, will be discussed.

\section{Contributing factors for overcrowded classrooms}

There are various factors that are contributing to the overcrowding of classrooms in South African schools. Some of those factors include the lack of teachers as well as inadequate infrastructure, such as insufficient schools and classrooms. When considering only public schools having government-employed teachers (excluding governing body appointed teachers), the average national LER stands at 33:1 (DBE 2014b:4). However, there are provinces such as KwaZulu-Natal with a concerning average of 39:1. The LER of Gauteng province (province of this case study) was slightly lower than the national average at 31.4:1. Some classes in South Africa have even reported an LER of 50:1 and higher (DBE 2014b:4). According to a National Early Childhood Development pilot project, 25:1 would be an appropriate LER within the South African context (Meier \& Marais 2012:117). In 2002, the then DoE (2002:4) was of the opinion that $40: 1$ would be the ideal LER because of the simultaneous teacher shortages and infrastructure deficiencies. The admission policy of 1998 that forms part of the National Education Act 27 of 1996 states that public primary schools should however not exceed an LER of 40:1 (Republic of South Africa 1996:s.p.). In reality, this number is exceeded by numerous schools within the Tshwane-West district in Gauteng, which served as the population from which the sample for this study was drawn.

According to Western countries, classes exceeding 30 learners are considered in need of reduction in their number of students because of the negative influence this feature can have on academic performance (Benbow et al. 2007:5). 
The Tennessee Student Teacher Achievement Ratio (STAR) project, which was conducted in the United States of America, concluded that classes with a ratio of 13-17:1 are defined as 'small' (Barbara, Hedges \& Konstantopoulos 2000:126). According to Meier and Marais (2012:117), acceptable international LERs differ according to age. For example, an LER of 9-15:1 is an acceptable LER for 5-year-olds (Grade $R$ learners). An acceptable LER for 6-year-olds and older is between 14:1 and 18:1. Meier and Marais (2012:117) are of the opinion that an LER above 18:1 will be an unacceptable LER, internationally. The Organisation for Economic Co-operation and Development (OECD) created a forum in which governments can work together to share experiences, research and seek solutions for problems, such as high LERs. The OECD has an average membership of over 34 countries, including Finland, Australia and the Netherlands, all of whom promote a lower LER in schools (OECD 2011:392). When comparing the LER in South Africa with international LERs, South Africa's average LER is much higher than the average of 16:1 in schools of OECD countries (OECD 2011:396)

When investigating the LER of a country, it is important that the growing learner enrolment rate is measured against the teacher graduation rate. It was predicted by the Centre for Development and Enterprise (CDE) that the South African teaching force will need to expand from around 426000 in 2013 to around 456000 in 2025 in order to meet the increased learner enrolment rate (Bernstein 2015:3). Green, Adendorff and Mathebula (2014:6) are of the opinion that the current LER of 33:1 in South Africa is not likely to decrease significantly over the next few years because of the lack of infrastructure and spike in learner enrolment rates. According to the CDE (Bernstein 2015:4) and Green et al. (2014:6), the teacher shortage is particularly severe in the Foundation Phase (grades R-3); the number of teacher graduates is too low to meet the needs of the phase. A major discrepancy was found between the supply and demand of Foundation Phase graduates from 2008 to 2012, in comparison to teachers qualifying for other school phases. Green et al. (2014:16) predicted that for an LER of 31:1 to be maintained for 2020, 147074 Foundation Phase teachers alone will be needed to accommodate the population expansion in 2020. According to Bernstein (2015:3), an increase of approximately 30000 teachers per year is needed over a 12-year period.

In combination with investigating teacher shortages and learner enrolment rates as contributing factors of overcrowdedness, it is also important to investigate current and future infrastructure availability. Current and future infrastructure also influences the LER and level of overcrowdedness in schools and classrooms. According to Abdoll and Barberton (2014:1), a dilapidated school infrastructure can be found 'across the country'. An example of the tremendous lack of infrastructure availability is a reported need for 6000 classrooms and 3000 libraries in the KwaZulu-Natal province alone (Jansen 2015:s.p.). In 2007, there was an estimated school infrastructure backlog of more than R7bn (Sebake, Mputlane \& Gibberd 2007:362). More recently, the backlog stands at R2 027048 (DBE 2019). According to a study by Abdoll and Barberton (2014:vii) that was commissioned by the Centre for Child Law because of insufficient reliable information and non-existing norms and standards on school infrastructure, precise statistics and numbers of the infrastructure backlog are unavailable. Skelton (2014:4) argues that the proof of lack of reliable information lies in the DBEs' inconsistent reports ranging from 395 to 510 'inappropriate structures'.

\section{The impact of class size and overcrowded classrooms}

According to Emmanuel (2013:11), the OECD (2011:392) and Skelton (2014:4), school infrastructure and the LER have a great impact on the quality of education, and are some of the most influential factors when considering increasing academic performance in classrooms. Overcrowded classrooms are also believed by Van Wyk (2008:143) to be a contributing factor to poor learning conditions because of the lack of space, fresh air and high noise levels that could lead to a lack of attention and even create stress within learners. Evidence proving this argument lies within the latest standardised tests including the PIRLS, where teachers provided feedback about their working conditions. Teachers reported on five potential problems, 'such as the building needing significant repair, overcrowding, and inadequate instructional materials' (Mullis et al. 2012:41). Teachers who reported 'hardly any problems' in their working conditions had learners in their classes achieving higher reading scores on an average than those teachers who reported 'moderate problems'. The experimental Tennessee STAR project is another convincing research project, demonstrating that the reduction of class size has a positive effect on learners' academic performance. Through their research and other prominent research from the OECD and Southern and Eastern Africa Consortium for Monitoring Educational Quality (SACMEQ) projects (Barbara et al. 2000:146-147; Dreyer \& Duminy 1983:158-159; Hungi 2011:21; OECD 2011:392; Van Wyk 2008:143), it was concluded that smaller classes, where students numbered below 20, produce better academic performance, such as improved reading skills. Benbow et al. (2007:5) confirmed this by noting that research has indicated that the academic performance improvements seen in young learners from smaller classes tend to sustain the academic performance improvements that are maintained till higher grades. Minorities and the disadvantaged learners, who are currently receiving education in predominantly rural or township areas in South Africa, with reportedly the poorest infrastructure and most overcrowded classrooms, are also believed to benefit the most from smaller classes (OECD 2011:392).

Cortes, Moussa and Weinstein (2012:25), Marais (2016:2) and Van Wyk (2008:143) are all of the opinion that overcrowded classrooms are one of the most common factors leading to didactical neglect, which refers to the teacher's inability to pay enough attention to each learner's educational needs. 
Improved academic performance is believed to occur as teachers can focus more on the needs of individual learners and the reduced time spent dealing with disruptions (OECD 2011:392). Smaller class sizes also help with other significant dynamics, such as increased differentiated instruction, improved classroom management and teacher morale (Vander Ark 2002:57). The reduction in the LER can also help increase the pass rate of learners (DoE 2008:xii, 70; Modisaotsile 2012:s.p.; Ndebele 2014:454). Therefore, achieving the LER of 33:1 in South Africa can be seen as a major challenge for the education system.

Neurobiological effects, for example, acute stress, hypertension, cognitive decline and psychological problems in learners and teachers because of overcrowdedness, have also been reported. According to Thompson and Haskins (2014:3), stress can arise from the chaos and unpredictability in close environments such as overcrowded classrooms. If the stress that a learner experiences within the classroom continues, it could lead to a learner avoiding (flight response) that subject or teacher, or even becoming aggressive towards the subject or person causing stress (fight response). There are various potential stressors within an overcrowded classroom, such as didactical neglect, noise level and over stimulation, which can have a direct influence on a learner. Given the influential effects of stress, this study deemed it necessary to further investigate possible stressful factors in overcrowded classrooms that could influence learning by investigating the fight or flight response.

\section{Theoretical framework}

This study was guided by the 'acute stress response' known as the fight or flight response. The 'fight or flight response' term, first developed by Dr Walter B Cannon in 1915, assisted the researcher with comprehending the challenges teachers and learners face within an overcrowded classroom. Thompson and Haskins' (2014) statement emphasises the importance of considering the fight or flight response as a theoretical framework when investigating learning within the classroom:

The reason some children have trouble paying attention in the classroom, remembering and following instructions and focussing their thinking has more to do with the neurobiological effects of stress hormones than with their unwillingness to do what the teacher says. (p. 4)

The fight or flight response is an important neurobiological reaction to stress that needs to be considered. According to Mash and Wolfe (2012:469), the fight or flight response refers to the immediate reaction of a person to protect themselves from potential harm, either by confronting the source of the danger (i.e. fight) or by escaping from the situation (i.e. flight). Stress can also be defined as the reaction of an organism to any demand that they feel they cannot cope with' (Lake 2012:106). The response to stress can have both a positive and a negative effect: normal stress (i.e. eustress) serves to increase learning and enhance memory. On the other hand, constant, chronic stress (i.e. distress) can have negative effects (Jensen 2011:56; Raffin 2009:350; Tsigos \& Chrousos 2002:866; Wolfe 2010:138, 141). Unrelenting or continuous stress (i.e. a stressful classroom environment on a daily basis) leads to the release of too much cortisol which can have a damaging effect, such as causing hypertension, psychological problems and even a cognitive decline. Learners who struggle with stress can exhibit problematic behaviour such as a lack of attention, boredom, a lack of discipline, tendency to fight and even vandalism (Marais 2016:5). These types of behaviour and feelings can impede the learner's cognitive ability to make academic achievements (Mash \& Wolfe 2012:192-194). If a child experiences any neurological or cognitive dysfunction or stress symptom, it could lead to severe challenges and learning barriers. Stress may also cause cognitive disturbances in children, including interference with academic performance, academic delays, attention disorders and other cognitive errors (Mash \& Wolfe 2012:416, 419). According to the Adverse Childhood Experiences (ACE) study regarding childhood exposure to traumatic stressors and later-life health and well-being, certain childhood experiences (such as stressful events) are major risk factors of the leading causes of illness and death, as well as poor quality of life (Centers for Disease Control and Prevention [CDC] 2016:s.p.).

Contributing factors to overcrowded classrooms, as alluded to above, gave rise to this qualitative empirical inquiry. The purpose of this study was to gather information regarding all the factors related to overcrowded classrooms, and the impact of overcrowded classrooms within the Foundation Phase schooling system.

\section{Method}

A qualitative research approach served this study best in view of the empirical inquiry that was launched to investigate a particular, naturally occurring phenomenon such as overcrowded classrooms (Nieuwenhuis 2010:75). Because McMillan and Schumacher (2010:323) indicate that inductive inquiry is emphasised during qualitative research studies, this interpretivist study gathered detailed particulars and then synthesised the data inductively in order to develop a deeper understanding of the problem (Delport \& De Vos 2014:49; Nieuwenhuis 2013:107).

The sample comprised 10 purposefully chosen individuals involved in Foundation Phase education in the Tshwane-West district, who are knowledgeable and experienced in teaching in overcrowded classrooms. The participants consisted of two Foundation Phase heads of department (HODs), two primary school principals, five lecturers from various higher education (HE) institutions and a DBE Tshwane-West district official. Indepth, semi-structured interviews were conducted for each of the participants. The semi-structured approach allowed the opportunity for participants to share spontaneous experiences, elaborate on their answers and share strategies that would prove to be useful in dealing with teaching in overcrowded classrooms (Egbert \& Sanden 2014:80). Data were transcribed to allow for all the details of the interviews to be captured, 
and for the identification of important word-for-word quotes from participants. During analysis of the transcribed data, audio and text elements were combined and analysed simultaneously using Atlas.ti software program, which led to more accurate findings because of Atlas.ti's systematic, structured and interactive platform. Inductive coding and a priori codes also assisted in analysing, categorising, testing and refining the collected data. Networks were then created to help determine cause and effect relationships, as well as associations between the codes. Networks are created by linking related codes, quotes, memos and comments made through the analysis process to one another. The networks then graphically visualise the possible themes that emerge from the data.

Data collection did not commence before written, informed consent was granted by all the participants. The participants were informed of their rights to withdraw from the study at any time, as well as of the researcher's responsibility to protect their anonymity. The university involved provided ethical clearance for the study to commence. No deception or manipulation of the data took place in order to validate the results. It is important to note that the findings discussed have certain limitations. Because this was a case study involving a small sample, generalisation of the findings is not possible. However, the study provides information on, and a description of, the challenges teachers might be facing within overcrowded Foundation Phase classrooms in South Africa. The study also makes suggestions about how these challenges experienced in overcrowded classrooms might be addressed. Therefore, if teachers are experiencing the same challenges as reported within this study, the findings might provide them with possible strategies in dealing with those challenges.

\section{Ethical consideration}

All of the participants gave informed and written consent. The College of Education Research Ethics Review Committee at the University of South Africa (reference no. 2016/04/13/53742184/20/MC) provided ethical approval along with the Department of Education. Anonymity and confidentiality were adhered to throughout the study.

\section{Findings and discussion}

In this section, the findings regarding teaching in overcrowded classrooms will be discussed. It was consistently stated by all the participants that overcrowdedness is a fundamental challenge within Foundation Phase classrooms. Two predominant themes came to light through the interviews: (1) challenges within overcrowded classrooms and (2) possible strategies for teaching in overcrowded classrooms.

\section{Theme 1: Challenges within overcrowded classrooms}

Table 1 presents an outline of the first theme: 'challenges within overcrowded classrooms', with its associated codes and sub-codes.

The issue regarding the challenges of overcrowded classrooms was described by a participant as placing '... tremendous amount of pressure on the teacher'. The participant further elaborated from her own personal experience:

'I was in a classroom once where there were more than 40 Foundation Phase learners in the class. The tables were from the back, against the wall up until the front, against the board. There were [sic] no space to move around, no space for playing or different working stations, etc. There the teacher had to cope with what she had, making quality teaching almost impossible. This makes teachers dispirited and lose hope.' (Participant 10, female, DBE official)

\section{Lack of infrastructure and a high learner-educator ratio}

Throughout this study, 'overcrowdedness' referred to the lack of infrastructure, such as a lack of classrooms as well as a high LER, referring to the number of learners per teacher in a classroom. The challenge of overcrowded classrooms was highlighted by all of the participants and described by one participant as making:

'[... T]eaching impossible. I'd say it prevents proper education from taking place within the classroom, because the classroom is too big - there is no space for moving, there is no space for children's suitcases, there are a lot of factors that play a role - the learners almost sit on top of each other - that lead [sic] to disciplinary problems and so on. I think it's the classrooms size and the number of children in a class that is definitely a negative aspect.' (Participant 2, male, school principal)

The participant interviews also brought to light the importance of considering the lack of resources within overcrowded classrooms. The lack of infrastructure and resources in schools and a high LER were all regarded by the participants as interrelated and part of a reciprocal process: 'it's a continuous struggle for the teacher'. The participants made it clear that:

'[A] teacher cannot handle 30 or more children. A teacher cannot even deal with so many learners, so this is where the greatest dysfunction in our schools come [sic] from.' (Participant 5, female, HE lecturer)

The participants' argument regarding a high LER is in line with Meier and Marais' (2012:117) statement that an LER of more than 25:1 is unacceptable and inappropriate.

\begin{tabular}{lll}
\hline Themes & Codes & Sub-codes \\
\hline $\begin{array}{l}\text { Challenges within } \\
\text { overcrowded classrooms }\end{array}$ & Lack of infrastructure and a high LER & - \\
& Impact of an overcrowded classroom (with a high LER) & Didactical neglect \\
& Problematic behaviour and a lack of discipline \\
& Negative teacher attitudes \\
\hline
\end{tabular}




\section{Impact of an overcrowded classroom (with a high learner-educator ratio)}

A high LER value leads to various challenges that teachers must face. The following challenges were identified by the participants as the result of a high LER in classrooms: didactical neglect, problematic behaviour and a lack of discipline, as well as negative teacher attitudes.

Didactical neglect as a result of an unbalanced LER was argued by researchers, such as Cortes et al. (2012:25), Marais (2016:2), Van Wyk (2008:143), as well as all the participants as being detrimental to learners' academic progress and development. Didactical neglect refers to the teacher's inability to pay enough attention to each learner's educational needs. The following statements made by the participants demonstrate the concerns of didactical neglect as a result of overcrowded classrooms with a high LER.

'To reach each child on their individual level within a large classroom makes it extremely difficult for the teacher and the child.' (Participant 1, male, HE lecturer)

'[We] do not differentiate, we follow the 'one shoe fits all' approach and then of course there is no integration, it is too much planning on top of all the administration and assessment of an overcrowded class.' (Participant 10, female, DBE official)

Didactical neglect also refers to the lack of differentiated learning and standardisation of learning content within Foundation Phase classrooms. Participants used phrases such as 'one size doesn't fit all...' to explain the extent of the problem. Participants stated that:

'[With] oversized classrooms, it is very difficult to teach and assess fully, never mind individually - you are not really on par with the children, which makes differentiation very difficult. It is usually your weaker learners who suffers [sic] from a lack of individual support.' (Participant 3, female, HOD)

'Teachers don't know, they can't tell you, who are the stronger candidates and who are the weaker learners due to the overcrowdedness of the classrooms.' (Participant 5, female, HE lecturer)

It was also recognised by the participants that overcrowded classrooms lead to increased problematic behaviour and a lack of discipline within the classroom. Problematic behaviour and discipline problems identified in a study conducted by Marais (2016:5) included a lack of attention, boredom, increased noise levels, fighting and even vandalising resources. All of the participants unanimously agreed that ' $[\mathrm{It}]$ is incredibly difficult to teach learners in overcrowded classrooms due to the continuous disruptions and interruptions'.

One participant explained that 'the high noise level within an overcrowded class is a [sic] enormous problem for teaching...' Other participants stated that:

'The smaller a class, the less the noise would be. Constructive interaction with the learners is impossible due to the amount of learners. Interaction leads to chaos instead of learning.' (Participant 7, female, school principal)
'Discipline is a real problem. The discipline is getting to a point where I've had a learner who assaulted a teacher at my school. I've even had students here who wrote letters stating - the teacher must fall - due to all the protest that have been taking place'. (Participant 2, male, school principal)

'An example of problematic discipline issues that I have observed at a school was that there were children walking around all the time, they came and went as they liked and it was concerningly [sic] a Foundation Phase classroom.' (Participant 10, female, DBE official)

The behaviour explained by the above quotations refers to the fact that in overcrowded classrooms teachers struggle to control and implement discipline strategies because of the high number of learners in the class. The problematic behaviour shown by learners in overcrowded classrooms resembles behaviour exhibited by learners who experience acute stress, resulting in a fight or flight response. Problematic behaviour because of stress can impede the learner's cognitive ability to attain academic achievements (Mash \& Wolfe 2012:192-194). If a child experiences any neurological or cognitive dysfunction or stress symptoms, it could lead to severe challenges and learning barriers. Stress may also cause cognitive disturbances in children, including interference with academic performance, academic delays, attention disorders and other cognitive errors (Mash \& Wolfe 2005:416, 419).

Lastly, negative attitudes of teachers were also identified as a concerning result of overcrowded classrooms. The personal beliefs and attitudes of teachers were identified as having a direct effect on motivation and commitment to quality teaching. One participant felt so strongly about the influence of a teacher's attitude on teaching and learning, that she argued that quality education is entirely reliant on 'the motivation and commitment of the teacher'. All of the above results of overcrowdedness were found to influence teachers' attitudes towards teaching. A teacher's motivation is also associated with a teacher's attitude. The participants argued that a decrease in motivation and a negative attitude are also because of the burden of administration and assessment related to overcrowded classrooms. One participant stated that 'around administration and your assessment, it all becomes just too much to handle'. The burdens of excess administration and assessment also align with didactical neglect as 'it is also very difficult to assess fully in oversized classrooms, you are giving no individual attention and have no idea what the learner's barriers or strengths are'.

The study participants argued that because of the overcrowdedness of the classroom, no individual support could be given or proper assessment could be conducted, leading to poor-quality teaching and didactical neglect. The excess administration and assessment associated with overcrowded classrooms, as well as constant changes made within the curriculum, were all influential factors related to teachers' attitudes and their decreasing motivation and commitment. These influential factors with regard to 
overcrowded classrooms can also be associated with the fight or flight behaviour presented by the teachers. The fight or flight response in this case refers to the demotivated reaction of teachers because of the challenges caused by teaching in overcrowded classrooms. When taking into account all the challenges associated with overcrowded classrooms, it is also necessary to investigate possible 'coping strategies' or solutions.

\section{Theme 2: Possible strategies for teaching in overcrowded classrooms}

This study enquired about possible solutions and strategies employed when dealing with overcrowded classrooms. Table 2 gives an outline of the second theme: 'possible strategies for teaching in overcrowded classrooms', with its associated codes and sub-codes. The first code relates to the broader level within the school, and the second code is at classroom level, as the responsibility of the teacher.

During the interviews it became evident that the participants felt that school management teams (SMTs) should start initiating more creative problem-solving solutions in order to assist teachers in dealing with the challenges they were facing because of overcrowdedness. The participants pointed out that it is the responsibility of everyone involved within the education system, including SMTs: 'It is the school-system that must help control this. It is not always in the hands of the teachers'. One participant stipulated that 'teamwork' was necessary to help improve teaching and learning in overcrowded classrooms.

\section{School management teams must increase creative problem-solving initiatives}

In light of the identified solution of SMTs initiating more problem-solving solutions, the following three strategies were identified by the participants for SMTs to implement within their schools. These include (1) the appointment of assistant teachers, (2) mentorship programmes and (3) effective 'in-service training'.

The appointment of assistant teachers was highly recommended by all of the participants. The participants expressed their belief that for teachers to be able to handle discipline problems and to feel less over-whelmed and burdened by the overcrowdedness of their classrooms, a second pair of hands was needed. Two participants described the need for assistant teachers as follows: 'you can't manage' and 'I don't think that we can cope' without the help of assistant teachers. At most schools, nothing can be done about the size of the classroom; therefore, a participant rooted for the appointment of assistant teachers as 'one of the best strategies or a first line of defence'. Another participant explained that appointing 'another teacher in a governing body position' would be like 'dividing a class into two'. Another participant agreed by stating that the class could be 'divided into groups and then the assistant teacher can take responsibility for some of the groups'. The appointment of assistant teachers could therefore decrease the LER from the current average of 33:1 to 33:2, which could in essence be calculated as 16:1.

From the data collected from the participants it can be inferred that with the appointment of assistant teachers, didactical neglect (as discussed in theme 1) will decrease. The assistant teacher will enable a teacher to accommodate more learners' needs as well as spend more time assisting learners who require more individual attention. 'Assistants can assist with differentiation. Each child can be accommodated, on every level', as explained by one of the participants. It was also stated that assistant teachers will be able to assist in various other classroom-related duties, such as discipline management, administrative duties and assessment. This will 'lighten the workload of the teacher to a great extent' and will help improve classroom 'discipline and consequently decrease the cognitive load of learners' by decreasing the noise levels within the classroom. By appointing assistant teachers, it would also have the advantage of improving teachers' attitudes and motivation, given that they will have the necessary support and assistance when dealing with the classroom challenges discussed in theme 1.

Effective mentorship programmes and in-service training was identified as another problem-solving initiative that SMTs can implement. One of the participants stated that 'there must be continual professional development; there must be mentors who are trained to support the teacher'. Mentorship programmes and in-service training could also empower teachers with the right tools to deal with problematic behaviour or discipline problems mostly associated with overcrowded classrooms. The implementation of an active and effective mentorship programme is not a new concept in the education system. However, it was identified by the participants as lacking in effectiveness within schools. Ineffectiveness of mentorship programmes has been ascribed

TABLE 2: Theme 2: Possible strategies for teaching in overcrowded classrooms.

\begin{tabular}{lll}
\hline Theme & Codes & Sub-codes \\
\hline $\begin{array}{l}\text { Possible strategies for teaching in } \\
\text { overcrowded classrooms }\end{array}$ & $\begin{array}{l}\text { School management teams (SMTs) must increase creative } \\
\text { problem-solving initiatives (school level) }\end{array}$ & Appointment of assistant teachers \\
& & Effective mentorship programmes \\
In-service training & Effective structuring of the classroom \\
& $\begin{array}{l}\text { Improved classroom management and discipline strategies } \\
\text { (classroom level) }\end{array}$ & Implementation of effective discipline strategies \\
& & Effective lesson planning \\
& Differentiated and inclusive lesson planning
\end{tabular}

Source: Pretorius, J., 2017, 'Teaching english as home language in overcrowded and multilingual foundation phase classrooms in the Tshwane-West District', M.Ed. dissertation, University of South Africa, Pretoria. 
to teachers being overworked and burdened with too many administrative and assessment duties as discussed in theme 1. It was explained by one of the participants that teachers will have to :

'[B]e remunerated and this will have to be negotiated with SMTs and school governing bodies, because it will have to be dedicated, experienced teachers and will be an addition to their workload. Their workload will also have to be distributed to ensure that they can fulfil this function.' (Participant 5, female, HE lecturer)

Another aspect of effective mentoring mentioned by a participant was 'peer mentoring'. The participant explained that:

'[T] $]$ he new trend, especially abroad, is mentoring and coaching or guiding, which is definitely a shortage in our country, where teachers peer-guide. More peer-guiding needs to be done, so that we can mentor each other and especially the novice teacher.' (Participant 9, female, HE lecturer)

Throughout the interviews it became evident that SMTs must take responsibility and implement more problem-solving initiatives in order to help minimise the damaging effects of overcrowdedness and empower teachers when teaching in such classes. The participants also recognised that teachers must take their own initiative and consistently implement improved, research-based classroom management and discipline strategies to help manage the challenging classroom realities.

\section{Improved classroom management and discipline strategies: The role of teachers}

With teachers being identified as the key role players with regard to the improvement of the teaching and learning environment, this study deemed it necessary to investigate the ways in which teachers themselves can bring about improvement. The role of teachers therefore includes (1) effective structuring of the classroom, (2) implementation of effective discipline strategies, (3) effective lesson planning and (4) differentiated and inclusive lesson planning.

Improved structuring of the classroom, such as the effective utilisation of available spaces and resources, was identified by the participants as a possible strategy that could help improve the learning and teaching environment. Teachers must think of creative ways in which to use their available spaces, 'teachers can even use the space outside of the class', such as the 'classroom patio' or 'the playgrounds'; those spaces can be used for 'language games' or 'group work'. Using available spaces outside of the classroom for some activities was approved for by another participant, who stated that it 'could help decrease the noise level in the classroom and also assist with the problem of overcrowdedness' and discipline-related problems.

A lack of discipline and its damaging impact were discussed in theme 1 as a problem related to overcrowdedness. Learners' problematic behaviour, such as lack of attention, boredom, lack of discipline, fighting and even vandalising resources (Marais 2016:5), can be related to overcrowded classrooms. The challenge and the importance of the implementation of effective discipline strategies were highly emphasised by all the participants. According to the participants, in order to manage an overcrowded classroom, you need to be 'very strict and firm, but there must still be a relaxed learning atmosphere'. One of the participants pointed out the importance of having self-discipline if you want to be able to manage an overcrowded class: 'in the first place, you need a lot of self-discipline, because you have to apply your discipline strategies consistent[ly]'. Other participants identified 'respect', 'commitment' and 'routine' as aspects that influence the success of teachers' discipline strategies. It was inferred from the data collected that the effective implementation of discipline strategies does not refer to the specifics of the discipline strategies, but rather about the way it is implemented. Teachers must commit to their strategies and implement them consistently from the beginning of the year. They must also take into account and respect the multicultural nature of their classrooms when implementing discipline-related strategies. Learners from different cultures view discipline and acceptable discipline strategies differently and teachers should be aware of this fact.

Another issue regarding improved classroom management and discipline involves effective planning and preparation when teaching in overcrowded classrooms. One participant explained that, 'if you are not well-prepared and you did not do enough planning, there will be chaos in your class'. Most of the participants placed emphasis on improved lesson planning as a possible strategy in helping to deal with the impact of overcrowdedness. One participant explained: 'in the first place, teachers must plan extensively. They must do extensive lesson planning'. Another participant agreed and explained that teachers are currently using pre-designed teaching series such as 'Platinum' and 'Oxford', which is part of the problem:

'[B]ecause if you receive planning from someone else, you don't really know what is going on. You have to do your own planning, plan your own lessons and know what you will need in order to make it understandable for your own learners', 'the learners that you know.' (Participant 6, female, HOD)

The participant elaborated further by explaining that those teaching series were planned for a learner 'who has the same mother tongue as [the Language of Learning and Teaching] LOLT of the school'. The content and teaching strategies planned for by the specific pre-designed series are then most of the time 'too difficult' and the teaching strategies are inappropriate for multilingual learners. One participant pointed out that 'a teacher may not teach, if she is not clear about her learning objectives and success criteria for the lesson'.

Another problem identified with using standardised teaching series is the 'one-size-fits-all' approach that is involved. The importance of doing your own planning and focussing your planning on the specific needs of the learners in your class relates to the importance of differentiated lesson 
planning as part of improved classroom management and discipline. Inclusivity as described by the 2001 Education White Paper 6 Special Needs Education: Building an Inclusive Education and Training System prescribes the use of differentiated learning styles and activities to ensure quality learning and involvement (DoE 2001:16; Joubert 2015:265; Killen 2010:31). Doing their own planning will enable teachers to implement inclusivity and differentiation by accommodating different learning abilities and styles. If teachers plan objectives for each lesson, they 'become more aware of the different needs that they need to include within their lesson planning'. Thus, possible fight or flight reactions of learners to the overcrowded classroom environment can be planned for and accommodated.

\section{Conclusion}

This study focused on overcrowdedness within Foundation Phase classrooms, an essential phase in learners' development, in the Tshwane-West district of South Africa. The teaching and learning challenges in overcrowded classrooms were investigated, and inferences were drawn from the qualitative data that were collected. Based on the research findings, the challenges participants teaching in overcrowded classrooms experienced were discussed, as well as practical solutions that SMTs and teachers can implement in order to assist with or solve the challenges of overcrowded classrooms. The importance and relevance of this study is evident in how it creates an awareness of the challenges teachers face, sometimes without any support or assistance. Furthermore, the study provides some solutions to these challenges.

The findings of this study conclude that a combined effort between all role players, such as the SMTs of a school and the teachers, could assist teachers in dealing with the challenges posed by overcrowdedness. As the participants pointed out, it is the responsibility of everyone involved within the education system to help solve problems. Practical recommendations presented in this study are based on two key role players in the education system: the SMTs and the teachers. It is recommended that SMTs appoint assistant teachers to help assist with the challenges teachers face because of overcrowdedness. The effective implementation of a mentorship programme and in-service training by the SMTs are further strategies that will assist, equip, support and empower teachers who are struggling with teaching in overcrowded classrooms. Active and effective mentorship programmes and in-service training could also empower and equip teachers with the right tools when dealing with discipline problems, mostly associated with overcrowded classrooms.

Recommendations for teachers included extensive planning with regard to classroom structuring, discipline strategies and lesson planning. A move away from standardised and pre-designed lesson plans is also advised to increase teachers' own initiative regarding planning and to account for differentiation. Effective structuring of the classroom and personalised lesson planning will in turn decrease the noise levels and disruptions within the classroom. More individual learner needs will be met, which will also prevent didactical neglect. Decreased noise levels, personalised lesson planning and meeting the needs of the individual learner will also help minimise potential fight or flight stressors within the overcrowded classroom. If the abovementioned strategies are implemented, a decrease in discipline problems associated with learners' fight or flight response could also be possible.

The researcher is confident that if the proposed strategies are implemented, they can improve teachers' working environments by providing sufficient support and assistance when facing the challenges of overcrowded classrooms. It could also decrease possible stressors that lead to problematic fight or flight behaviour, and thus create a better learning environment for learners. However, If SMTs and teachers do not start implementing the recommendations suggested in this study, overcrowdedness will, for some years to come, remain the Achilles heel of the South African education system.

Future studies should investigate challenges and solutions related to overcrowded classrooms in other areas in South Africa, and in other phases of schooling. Future studies could also identify successes in teaching and learning in overcrowded classrooms, which could help inform teachers' teaching strategies in overcrowded classrooms as well as teacher education curriculums.

\section{Acknowledgements}

This article is adapted from a master's thesis at the University of South Africa. Joyce West expresses her sincere appreciation, gratitude and thanks to her supervisor Prof. Corinne Meier for the guidance, support and motivation provided. She would also like to thank Louise Greyling for all her effort and insight regarding the editing of this article.

\section{Competing interests}

The authors declare that they have no financial or personal relationships that may have inappropriately influenced them in writing this article.

\section{Authors' contributions}

J.W. wrote the article under the full supervision and guidance of Prof. C.M.

\section{Funding information}

The University of Pretoria provided the necessary funding for publication.

\section{Data availability statement}

Data sharing is not applicable to this article as no new data were created or analysed in this study. 


\section{Disclaimer}

The views and opinions expressed in this article are those of the authors and do not necessarily reflect the official policy or position of any affiliated agency of the authors.

\section{References}

Abdoll, C. \& Baberton, C., 2014, Mud to bricks: A review of school infrastructure spending and delivery, Pretoria University Law Press, Pretoria.

Barbara, N., Hedges, L.V. \& Konstantopoulos, C., 2000, 'The effects of small classes on academic achievement: The results of the Tennessee class size experiment', American Educational Research Journal 37(1), 123-151. https://doi.org/ 10.3102/00028312037001123

Benbow, J., Mizrachi, A., Oliver, D. \& Moshiro, L.S., 2007, Large class sizes in the developing world: What do we know and what can we do? viewed 23 April 2015, from https://www.equip123.net/docs/E1-LargeClassrooms.pdf.

Bernstein, A., 2015, Centre for development and enterprise: Teachers in South Africa: Supply and demand 2013-2025, viewed 10 November 2015, from https:/WwW. cde.org.za/wp-content/uploads/2015/03/Final-Revised-ES-TeacherSupply andDemand2025.pdf.

Centers for Disease Control and Prevention (CDC), 2016, Adverse childhood experiences (ACE) study. National Center for Chronic Disease Prevention and Health Promotion, viewed 03 December 2017, from https://www.cdc.gov/ace/.

Cortes, K.E., Moussa, W.S. \& Weinstein, J.M., 2012, 'Making the grade: The impact of classroom behaviour on academic achievement', paper presented at the APPAM Fall Research conference, Baltimore, MD, 8-10 November, viewed 10 Octobe 2016, from https://www.appam.org/events/fall-research-conference/2012/.

Delport, C.S.L. \& De Vos, A.S., 2014, 'Professional research and professional practice', in A.S. De Vos, H. Strydom, C.B. Fouché \& C.S.L. Delport (eds.), Research at grass roots: For the social sciences and human service professions, 8th edn., pp. 45-60, Van Schaik, Pretoria.

Department of Basic Education (DBE), 2013, Annual performance plan 2013/2014 Department of Basic Education, Johannesburg.

Department of Basic Education (DBE), 2014a, Report on the annual nationa assessment of 2014, Department of Basic Education, Pretoria.

Department of Basic Education (DBE), 2014b, School realities of 2014: Quality statistics for education, Department of Basic Education, Pretoria.

Department of Basic Education (DBE), 2019, Estimates of national expenditure, viewed 14 January 2020, from https://www.treasury.gov.za/documents/ National\%20Budget/2019/ene/Vote\%2014\%20Basic\%20Education.pdf.

Department of Education (DoE), 2001, White Paper 6: Special needs education Department of Education, Pretoria.

Department of Education (DoE), 2002, Post distribution model for the allocation of educator posts to schools: Regulation 1451, viewed 12 February 2016, from https://www.education.gov.za/Portals/0/Documents/Legislation/Regulations/ Regulation\%201451\%20of\%202002.pdf?ver=2008-03-05-110912-000.

Department of Education (DoE), 2008, Ministerial committee on learner retention in the South African schooling system, Department of Education, Pretoria.

Dreyer, H.J. \& Duminy, P.A., 1983, Education 2: A course in psych pedagogics, Maskew Miller Longman, Cape Town.

Egbert, J. \& Sanden, S., 2014, Foundations of education research: Understanding theoretical components, Routledge, New York, NY.

Emmanuel, A.O., 2013, 'Effect of student-teacher ratio on students' academic performance in secondary schools in the Ado-Odo/Ota Local Government area of Ogun State', NOUN. M.Ed. dissertation, National Open University of Nigeria, Lagos.

Green, W., Adendorff, A. \& Mathebula, B., 2014, “"Minding the gap?” A national foundation phase teacher supply-demand analysis 2012-2020', South African Journal of Childhood Education 4(2), 1-23. https://doi.org/10.4102/sajce.v4i3.222

Hungi, N., 2011, SACMEQ: Accounting for variations in the quality of primary school education, viewed 15 August 2015, from https://www.sacmeq.org/sacmeqprojects/sacmeq-iii/reports\#.

Jansen, L., 2015, Schools backlog plan unrealistic, viewed 02 December 2017, from https://www.iol.co.za/news/politics/schools-backlog-plan-unrealistic-1871999.

Jensen, E., 2011, Different brains, different learners: How to reach the hard to teach, 2nd edn., Corwin, San Diego, CA.

Joubert, I., 2015, Geletterdheid in die grondslagfase, 2de hersiene uitgawe, Van Schaik, Pretoria.
Killen, R., 2010, Teaching strategies for quality teaching and learning, Juta, Claremont, CA.

Lake, M., 2012, 'Anxiety, obsessive-compulsive and trauma related disorders', in A. Burke (ed.), Abnormal psychology: A South African perspective, pp. 100-151, Oxford, Cape Town.

Marais, P., 2016, “"We can't believe what we see": Overcrowded classrooms through the eyes of student teachers', South African Journal of Education 36(2), 1-10. https://doi.org/10.15700/saje.v36n2a1201

Mash, E.J. \& Wolfe, E.J., 2012, Abnormal child psychology, 4th edn., Wadsworth, Belmont.

McMillan, J.H. \& Schumacher, S., 2010, Research in education: Evidence-based inquiry 7th edn., Pearson, Boston, MA.

Meier, C. \& Marais, P., 2012, 'Managing learners in early childhood development', in C. Meier \& P. Marais (eds.), Education management in early childhood development, 2nd edn., pp. 111-125, Van Schaik, Pretoria.

Modisaotsile, B.M., 2012, The failing standards of basic education in South Africa viewed 20 January 2015, from https://www.ai.org.za/wp-content/uploads/ downloads/2012/03/No.-72.The-Failing-Standard-of-Basic-Education-in-SouthAfrica1.pdf.

Mullis, I.V., Martin, M.O., Foy, P. \& Drucker, K.T., 2012, PIRLS 2011: International results in reading, International Study Centre, Boston College, Chestnut Hill, MA, viewed 20 April 2015, from https://timssandpirls.bc.edu/pirls2011/downloads/P11_IR FullBook.pdf.

Mullis, I.V., Martin, M.O., Foy, P. \& Hooper, M., 2017, PIRLS 2016: International results in reading. International Study Centre, Boston College, Chestnut Hill, MA, viewed 02 January 2018, from https://timssandpirls.bc.edu/pirls2016/internationalresults/.

Nieuwenhuis, J., 2010, 'Qualitative research design and data gathering techniques', in K. Maree (ed.), First steps in research, rev. 4th impression, pp. 67-97, Van Schaik, Pretoria.

Nieuwenhuis, J., 2013, 'Analysing qualitative data', in K. Maree (ed.), First steps in research, 3rd edn., pp. 98-122, Van Schaik, Pretoria.

Ndebele, T., 2014, 'Education', in F. Cronje, J. Kane-Berman \& L. Moloi (eds.), South Africa survey 2014/2015, pp. 419-530, Institute of Race Relations, Johannesburg.

Organisation for Economic Co-operation and Development (OECD), 2011, Education at a glance: What is the student-teacher ratio and how big are classes? viewed 31 May 2015, from https://www.oecd.org/edu/skills-beyond-school/48631144.pdf.

Pretorius, J., 2017, 'Teaching english as home language in overcrowded and multilingual foundation phase classrooms in the Tshwane-West District', M.Ed. dissertation, University of South Africa, Pretoria.

Raffin, N.J., 2009, Children and stress: Caring strategies to guide children, Virginia State University, Petersburg, VA, viewed 15 June 2015, from https://vtechworks. lib.vt.edu/handle/10919/49520.

Republic of South Africa, 1996, National Education Policy Act, 1996 (Act 27 of 1996) viewed 10 June 2015, from https://www.education.gov.za/Portals/0/Documents/ Legislation/Acts/NATIONAL\%20EDUCATION\%2OPOLICY\%20ACT,\%20NO\%20 27\%200F\%201996,\%2028\%2010\%202011.pdf?ver=2015-01-30-102109-667.

Sebake, T.N., Mphutlane, L. \& Gibberd, J.T., 2007, Developing a school infrastructure performance indicator system (SIPIS), viewed 02 December 2017, from https:// citeseerx.ist.psu.edu/viewdoc/download?doi=10.1.1.566.4109\&rep=rep1\& type=pdf.

Skelton, A., 2014, 'Leveraging fuds for school infrastructure: The South African "mud schools" case study', in UKFIET international conference on education and development: Education and development post 2015: Reflecting, reviewing, revisioning, Oxford, 10-12 September 2013.

Thompson, R.A. \& Haskins, R., 2014. 'Early stress gets under the skin: Promising initiatives to help Children facing chronic adversity', Future of Children 24(1), $1-8$

Tsigos, C. \& Chrousos, G.P., 2002, 'Hypothalamic-pituitary-adrenal axis, neuroendocrine factors and stress', Journal of Psychosomatic Research 53(4), 865-871. https://doi.org/10.1016/S0022-3999(02)00429-4

Vander Ark, T., 2002, 'The case for small high schools', Educational Leadership 59(5), 55-59.

Van Wyk, P.C., 2008, 'The didactically neglected child', in J.A. Kapp (ed.), Children with problems: An orthopedagogical perspective, pp. 133-144, Van Schaik, Pretoria.

Wolfe, P., 2010, Brain matters: Translating research into classroom practice, 2nd edn., Association for Supervision and Curriculum Development, Alexandria, VA. 